\title{
Correction to: Development of a new risk nomogram of perioperative major adverse cardiac events for Chinese patients undergoing colorectal carcinoma surgery
}

Juhong Zhang ${ }^{1,2} \cdot$ Ying Xiao $^{3} \cdot$ Daya Yang $^{1} \cdot$ Xiaodong Zhuang $^{1} \cdot$ Ling Wang $^{1} \cdot$ Xiuren Gao $^{1,2} \cdot$ Zhibin Huang $^{1,2}$

Published online: 23 June 2018

(C) Springer-Verlag GmbH Germany, part of Springer Nature 2018

Correction to: Int J Colorectal Dis (2017) 32:1157-1164

https://doi.org/10.1007/s00384-017-2812-x

The original version of this article, unfortunately, contained an error.

On this article the authors requested to add another affiliation which is Key Laboratory on Assisted Circulation, Ministry of Health, Guangzhou 510080, China for Juhong Zhang, Xiuren Gao and Zhibin Huang. The new affiliation is now added in this article.

The remainder of the article remains unchanged.

The online version of the original article can be found at https://doi.org/ $10.1007 / \mathrm{s} 00384-017-2812-\mathrm{x}$

\footnotetext{
Xiuren Gao

zsfygxr@163.com

$\triangle$ Zhibin Huang

huangzb2015@163.com

1 Department of Cardiology, The First Affiliated Hospital of Sun Yat-sen University, No. 58 Zhongshan 2nd Road, Guangzhou 510080, China

2 Key Laboratory on Assisted Circulation, Ministry of Health, Guangzhou 510080, China

3 Department of Anesthesiololgy, The First Affiliated Hospital of Sun Yat-sen University, No. 58 Zhongshan 2nd Road,

Guangzhou 510080, China
} 